\title{
Research on the Establishment of Carbon Emission Management Model Based on the Construction Process-Taking a Stadium for the 2022 Beijing Winter Olympic Games as an Example
}

\author{
Bin $\mathrm{Xu}^{1,2^{*}}$, Tianyuan Feng, and Wenting $\mathrm{Yi}^{1}$ \\ ${ }^{1}$ China Architecture Design \& Research Group, Beijing, 100044, China \\ ${ }^{2}$ Beijing University of Civil Engineering and Architecture, Beijing 100044, China
}

\begin{abstract}
At present, there are few systematic studies on carbon emission management of construction projects, which can no longer meet the requirements of carbon emission management of the construction of stadiums for Winter Olympics. This paper, taking a stadium for Winter Olympics as an example, discusses the boundaries, scenario setting and accounting methods of carbon emissions in the construction process. And then, we construct the management model and management system of carbon emissions. In this case, the monitoring and collection of carbon emissions and carbon emission reduction measures will be promoted to efficiently finalize the carbon emission pipes for the construction of Winter Olympics stadiums. The management model, technical measures and management system of carbon emissions suitable for Winter Olympics stadiums developed in this research can be further studied and widely applied to carbon emission management in the construction process of various public buildings.
\end{abstract}

\section{Introduction}

In recent years, as global warming has been intensified, polar glaciers have continued to melt, resulting in the rise in sea levels and extreme weather, which has posed impact on natural ecosystems, agricultural systems, energy systems and even human health to varying degrees. Reduction of greenhouse gas emissions such as $\mathrm{CO}_{2}$ emission, as an important measure to deal with global climate change, has attracted worldwide attention. The urban area in the world accounts for only $4 \%$ of the surface of the earth, but its greenhouse gas emissions contribute to up to $70 \%$ of the whole ${ }^{[1]}$. This shows that cities are already one of the main sources of carbon emissions. Among them, as an important component of the city, buildings can produce carbon emissions that cannot be underestimated. It is predicted that the greenhouse gases generated by the construction industry will account for $25 \%$ of the total emissions of the whole society by $2030^{[2]}$.

In the total life cycle of the building, there is no physical carbon emission in the planning and design stage, but a huge portion of carbon emissions will be generated in the construction, operation and demolition stages. At present, most of the researches on emissions of buildings in China only focus on $\mathrm{CO}_{2}$ emissions in the process of building operation and few of them put the emphasis on the construction stage lacking actual engineering cases of carbon emission management in the construction stage. Therefore, taking a stadium of the 2020 Beijing Winter Olympics as an example, this paper systematically discusses the objective setting, scope establishment, carbon emission accounting method and working system establishment of carbon emission management in the construction stage, and then constructs and forms the management model of carbon emissions in the construction stage.

\section{Objectives and principles of carbon Emission management}

\subsection{Objectives of carbon emission management}

The International Olympic Committee has proposed to reduce direct and indirect carbon emissions to achieve the objective of carbon emission management of being carbon-neutral. Therefore, all previous Olympic hosts have attached great importance to the issue of carbon emissions during the whole process of hosting the Olympics. In London Olympics and Sochi Winter Olympics, $100 \%$ carbon offsetting has been realized. Among them, the London Olympics is the first Olympic Games in history to measure carbon emissions throughout the period. The 2020 Tokyo Winter Olympics also has promised to take measures to maintain carbon dioxide emissions in Tokyo at zero within the 4 days of the opening and closing ceremonies and shows their positive attitude towards global warming.

As the host cities of the 2022 Winter Olympics, Beijing and Zhangjiakou have clearly included the sustainable development into the development concept of the Winter Olympics. Among them, carbon

\footnotetext{
* Corresponding author: xubin@cadg.cn
} 
management is an important part of sustainable development. Therefore, the 2020 Winter Olympics also pays much attention to carbon dioxide emissions and management and formulates the "The Carbon Management Plan for the Olympic and Paralympic Winter Games Beijing 2022", which aims to achieve carbon offsetting and zero carbon emissions through carbon emission reduction and carbon offset measures. The Beijing Organizing Committee for the 2022 Olympic and Paralympic Winter Games regards stadium construction as a crucial part of the preparations for the 2022 Beijing Winter Olympics. Its carbon management objectives are consistent with the overall carbon management objectives of the Beijing Winter Olympics, that is, by optimizing carbon emissions in the process of stadium construction, to help Beijing realize zero carbon emissions in Winter Olympics.

\subsection{Principles of carbon emission management}

According to the overall arrangement of carbon management for the Beijing Winter Olympics, in order to quantify and report the carbon emission status during the process of stadium construction, strategies and engineering, technology and management measures of carbon emission reduction are applied to promote the realization of the carbon offsetting. This research refers to related methodologies at enterprise and organizational levels of ISO16064, as well as relevant methodologies and standards at the national, city and Beijing local levels, and puts forward the principles of carbon emission assessment for a stadium of Beijing Winter Olympics, mainly including six principles of correlation, completeness, consistency, accuracy, transparency and avoidance of repetition.

Table 1. Assessment Principles and Specific Requirements for Carbon Emissions of a Stadium of 2020 Beijing Winter Olympics

\begin{tabular}{|c|c|c|}
\hline $\begin{array}{c}\text { Serial } \\
\text { Number }\end{array}$ & Principles & Specific Requirements \\
\hline 1 & Correlation & $\begin{array}{l}\text { - Whether to include carbon } \\
\text { emissions associated with } \\
\text { winter Olympic activities, and } \\
\text { to determine carbon emission } \\
\text { assessment boundaries, such as } \\
\text { organizational boundaries and } \\
\text { operational boundaries. } \\
\text { - Whether to consider all } \\
\text { carbon emission activity level } \\
\text { data and all of the evaluation } \\
\text { methods are available. }\end{array}$ \\
\hline 2 & Completeness & $\begin{array}{l}\text { - Whether to meet the } \\
\text { boundary requirements of the } \\
\text { carbon emission range in } \\
\text { international and domestic } \\
\text { emission standards. } \\
\text { - Whether it covers the } \\
\text { boundary of previous Olympic } \\
\text { Carbon emission accounting. } \\
\text { - Whether all carbon emissions } \\
\text { associated with winter } \\
\text { Olympics activities are } \\
\text { included within accounting }\end{array}$ \\
\hline
\end{tabular}

\begin{tabular}{|c|c|c|}
\hline & & $\begin{array}{l}\text { boundaries. At the same time } \\
\text { considering the importance } \\
\text { and availability of data. }\end{array}$ \\
\hline 3 & Consistency & $\begin{array}{l}\text { - Whether in line with } \\
\text { international and domestic } \\
\text { standard methodology. } \\
\text { - Whether the accounting } \\
\text { methods are comparable and } \\
\text { consistent from year to year. } \\
\text { - Whether the accounting } \\
\text { boundaries are clear and } \\
\text { consistent. }\end{array}$ \\
\hline 4 & Accuracy & $\begin{array}{c}\text { - Whether the activity level is } \\
\text { the data which is sufficient and } \\
\text { has enough precision. } \\
\text { - Whether the activity level } \\
\text { data is repeatable and can be } \\
\text { verified by third parties. }\end{array}$ \\
\hline 5 & Transparency & $\begin{array}{l}\text { - Whether the carbon emission } \\
\text { information is clear, neutral } \\
\text { and objective. } \\
\text { - Whether the data acquisition, } \\
\text { recording and its method } \\
\text { choice way is clear. }\end{array}$ \\
\hline 6 & $\begin{array}{c}\text { Avoidance of } \\
\text { Repetition }\end{array}$ & $\begin{array}{l}\text { - Whether to consider avoiding } \\
\text { double-counting. }\end{array}$ \\
\hline
\end{tabular}

\section{Scope definition of carbon emission management}

\subsection{Establishment of time boundaries}

The total life cycle of the building starts from the formulation of the project proposal, and goes through various stages such as feasibility study, design, purchasing by invitation to bid, construction and installation, use and maintenance, demolition and disposal. It covers the whole process from planning to demolition, which all affect the realization of the whole function of the total life cycle of the building ${ }^{[3]}{ }^{[4]}$. Based on the realities of the construction of a stadium for the 2020 Beijing Winter Olympics, this research defines the time of accounting for carbon emission management in the construction stage of the stadium as the construction and installation stage of the stadium and the surrounding municipal supporting infrastructure.

\subsection{Establishment of organizational boundaries}

Stadium builders need to set organizational boundaries according to actual construction conditions, so as to make it clear what construction activities are included for the calculation and reporting of greenhouse gas emissions. Generally, enterprises use two methods to determine the organizational boundaries in GHG Protocol, namely the equity share method and right of control method ${ }^{[5]}$. In the scenario of engineering construction, obviously it is more appropriate to adopt the right of control method, that is, the engineering construction activities managed by stadium construction units are included in the scope of carbon emission 
management. According to the principle of right of control, the carbon emission management of the Winter Olympics stadium mainly covers the greenhouse gas emissions generated by the construction of the stadium and its surrounding facilities.

\subsection{Selection of sources of carbon emissions}

\subsubsection{Scope of Greenhouse Gas Protocol}

The GHG Protocol mainly focuses on three categories of greenhouse gas emissions (Table 2) which include direct emission sources and indirect emission sources, and also include carbon dioxide emissions caused by various types of sources, thus making the objectives of GHG Protocol and control more focused. Among them, the emission sources in Category 1 and Category 2 are relatively easy for statistics and accounting, but the emission sources in Category 3 have been less applied for accounting in China and thus are relatively difficult for accounting. In the subsequent accounting, factors such as the availability of emission factors, and the large amount of production of measurable activity level data will be comprehensively considered to screen out and identify the main emission sources for statistics, accounting and control.

Table 2. Scope of the GHG Protocol

\begin{tabular}{|c|c|c|}
\hline $\begin{array}{c}\text { Serial } \\
\text { Number }\end{array}$ & Name & Specific Content \\
\hline 1 & $\begin{array}{c}\text { Category } \\
1\end{array}$ & $\begin{array}{c}\text { Direct greenhouse gas emissions, } \\
\text { such as gasoline, diesel, natural } \\
\text { gas and other fossil fuels } \\
\text { combustion. }\end{array}$ \\
\hline 2 & $\begin{array}{c}\text { Category } \\
2\end{array}$ & $\begin{array}{c}\text { Indirect emissions of greenhouse } \\
\text { gases caused by energy use, such } \\
\text { as self-use purchased heat, } \\
\text { electricity, steam, etc. }\end{array}$ \\
\hline 2 & $\begin{array}{c}\text { Category } \\
3\end{array}$ & $\begin{array}{c}\text { Other indirect greenhouse gas } \\
\text { emissions, such as raw materials } \\
\text { purchased for construction, } \\
\text { vehicle transportation and waste } \\
\text { disposal. }\end{array}$ \\
\hline
\end{tabular}

\subsubsection{Criteria for selection of carbon emission sources}

As for the selection of emission sources, since each nation or city has formulated standards according to its own characteristics, there are various statistical forms and types on the activity level data of greenhouse gas emissions from the same emission source. Therefore, after comprehensively assessing the level and capacity of China's greenhouse gas statistical accounting, and considering the experience in the selection of emission sources in previous Olympic Games, the decision tree for carbon emission source discrimination of the Winter Olympics stadium is formulated and shown in Figure 1.

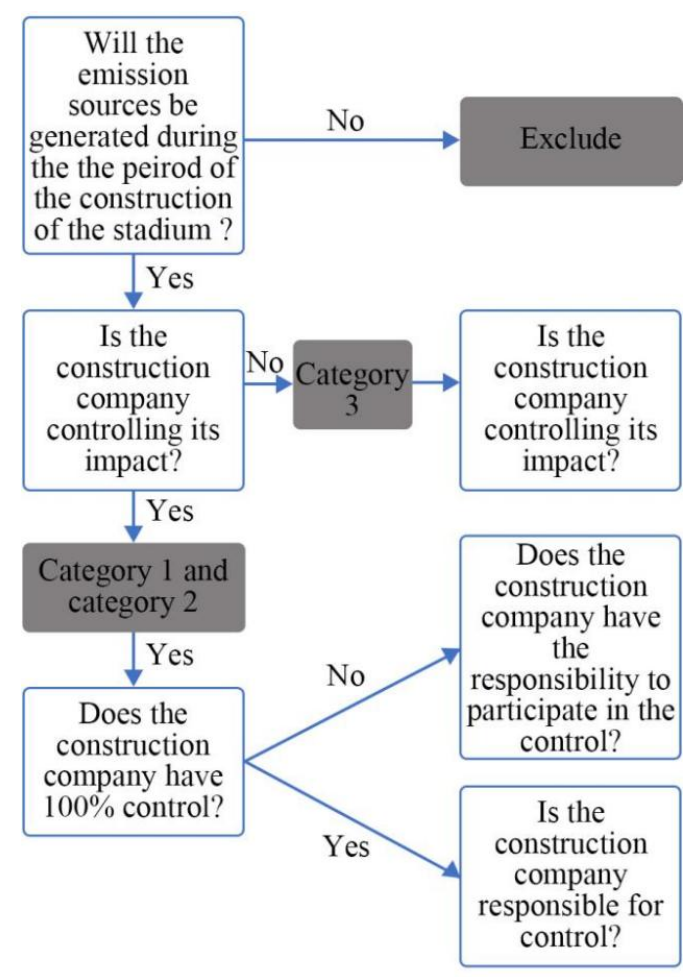

Fig. 1. Decision tree for carbon emission source discrimination

Then, the carbon emission sources generated during the construction of the stadium are categorized and discriminated according to the decision tree of carbon emission source discrimination, and the categorized results are shown in Figure 2. The carbon emission sources during the construction of the stadium are divided into energy and non-energy categories. In the sub-categories, the scope of each carbon emission source is determined according to ISO14064-1 standard and GHG Protocol standard.

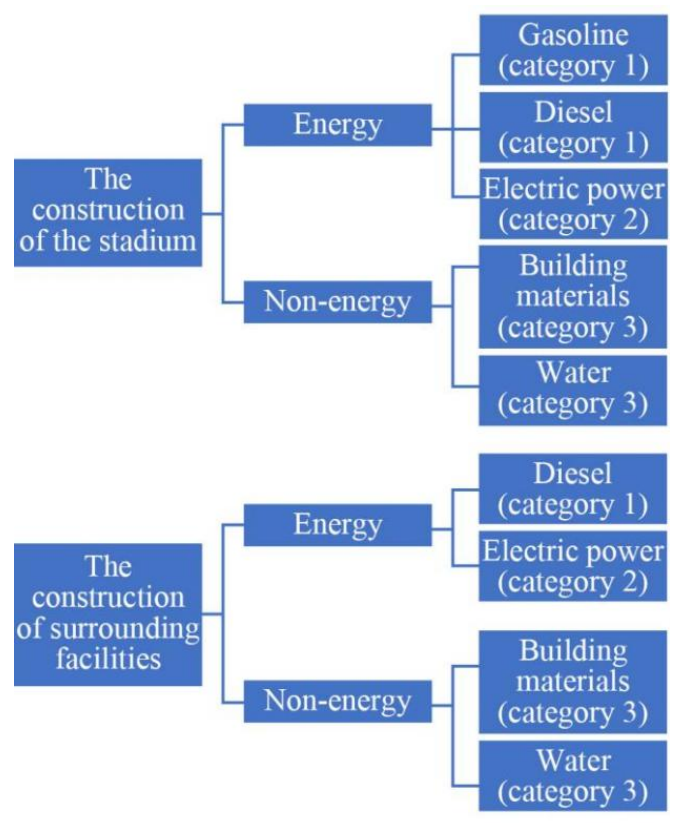

Fig. 2. Categorization of emission sources of a Stadium for the 2022 Winter Olympics 


\section{Calculation method of carbon emissions}

\subsection{Calculation method of carbon emissions}

The methodology of carbon emission calculation mainly refers to previous Olympic Games and the carbon footprint and carbon offsetting standard systems based on organizations or products such as ISO 14064-1, PAS 2050 and PAS 2060. The main basis can be divided into three levels: international, domestic and local, as shown in Table 3.

Table 3. Carbon Emission Standard System

\begin{tabular}{|c|c|}
\hline Classification & Carbon emission standard system \\
\hline \multirow{5}{*}{$\begin{array}{l}\text { International } \\
\text { level }\end{array}$} & $\begin{array}{l}2006 \text { IPCC Guidelines for National } \\
\text { Greenhouse Gas Inventories }\end{array}$ \\
\hline & ISO 14064-1 \\
\hline & GHG Protocol \\
\hline & $\begin{array}{c}\text { London } 2012 \text { Carbon Management } \\
\text { Methodology }\end{array}$ \\
\hline & $\begin{array}{l}\text { Pyeongchang } 2018 \text { Carbon Footprint } \\
\text { Methodology }\end{array}$ \\
\hline \multirow{3}{*}{ Domestic level } & $\begin{array}{c}<\text { Guidelines for the Preparation of } \\
\text { Provincial GHG Inventories (Trial) }>\end{array}$ \\
\hline & $\begin{array}{l}<\text { Notice on The Issuance of The First } \\
\text { Batch of GHG Emission Accounting } \\
\text { Methods and Reporting Guidelines for } \\
\text { Enterprises in } 10 \text { Industries (Trial) }> \\
\text { (NDRC Climatology [2013] NO. 2526) }\end{array}$ \\
\hline & $\begin{array}{c}\text { Circular on the Issuance of the Third } \\
\text { Batch of GHG Accounting Methods and } \\
\text { Reporting Guidelines for Enterprises in } 10 \\
\text { Industries (Trial) }\end{array}$ \\
\hline \multirow{2}{*}{ Local level } & $\begin{array}{c}\text { Guidelines for Carbon Dioxide } \\
\text { Accounting and Reporting of Enterprises } \\
\text { (units) in Beijing }\end{array}$ \\
\hline & $\begin{array}{l}\text { Work Manual of Beijing Fixed Asset } \\
\text { Investment Project Energy Conservation } \\
\text { and Low-carbon Assessment and Review }\end{array}$ \\
\hline
\end{tabular}

The accounting of the stadium adopts the carbon emission factor method first proposed by IPCC. Its basic idea is to construct the activity data and emission factor for each emission source according to the carbon emission lists, and take the product of the activity data and emission factor as the estimated value of carbon emissions of this emission project. The calculation method is relatively simple, with a wide range of factor bases and relatively accurate results. It is one of the widely used methods in research on measurement of carbon emissions at present, and also a relatively effective means to measure carbon emissions of a single building.

The basic calculation formula of carbon emission factor method is as follows:

$$
\text { Emissions }=\sum A D_{\mathrm{i}} \times E F_{\mathrm{i}}
$$

Where:

Emissions-Carbon emissions from the building, Unit: $\operatorname{kgCO} 2$;

$\mathrm{AD}_{\mathrm{i}}$-Activity data of category i, Unit: $\mathrm{kWh} / \mathrm{m}^{2}$;

$\mathrm{EF}_{\mathrm{i}}$-Emission factor of category $\mathrm{i}$ activity data, Unit: $\mathrm{kgCO} 2 / \mathrm{kWh}$.

\subsection{Carbon emission factors}

The carbon emission factors of indirect emission sources such as electricity, thermodynamics and building materials have certain regional differences. Meanwhile, a certain database of carbon emission factors cannot cover all carbon emission sources. Therefore, in the selection process of factors in the stadium, in order to rationally select the carbon emission factors from various sources in the calculation, the priority principle is formulated, that is, priority should be given to the factors published in official documents such as policies and guidelines of relevant government departments including the National Development and Reform Commission and the Beijing Municipal Commission of Development and Reform. Secondly, the emission factors reported in domestic research reports and literatures should be selected, and the carbon emission factors published in previous Olympic Games and foreign authoritative databases should be referred to. Consequently, the table of some carbon emission factors for the Winter Olympics stadium is as follows.

Table 4. Carbon Emission Factors

\begin{tabular}{|c|c|l|c|}
\hline Name & $\begin{array}{c}\text { Carbon } \\
\text { Emission } \\
\text { Factors }\end{array}$ & Unit & Data Sources \\
\hline Cement & 0.71 & $\mathrm{~kg} / \mathrm{kg}$ & $\begin{array}{c}\text { Environmental } \\
\text { Labeling Products } \\
\text { Technical } \\
\text { Requirements of } \\
\text { Cement }\end{array}$ \\
\hline Steel & 1.8 & $\mathrm{~kg} / \mathrm{kg}$ & $\begin{array}{c}\text { Domestic Database } \\
\text { (National } \\
\text { Verification Data) }\end{array}$ \\
\hline Copper & 3.69 & $\mathrm{~kg} / \mathrm{kg}$ & $\begin{array}{c}\text { Domestic Database } \\
\text { (National } \\
\text { Verification Data) }\end{array}$ \\
\hline Gravel & 0.002425 & $\mathrm{~kg} / \mathrm{kg}$ & $\begin{array}{c}\text { China LCA Database } \\
\text { CLCD }\end{array}$ \\
\hline $\begin{array}{c}\text { Seals } \\
\text { and } \\
\text { adhesives }\end{array}$ & 3.85 & $\mathrm{~kg} / \mathrm{kg}$ & $\begin{array}{c}\text { London Olympic } \\
\text { Games }\end{array}$ \\
\hline Diesel & 3.13 & $\mathrm{tCO} / \mathrm{t}$ & $\begin{array}{c}\text { Guidelines for } \\
\text { Accounting and } \\
\text { Reporting of Carbon } \\
\text { bioxide Emissions } \\
\text { Enterprises (units) } \\
\text { in Beijing }\end{array}$ \\
\hline Gasoline & 2.93 & $\begin{array}{c}\text { Guidelines for } \\
\text { Accounting and } \\
\text { Reporting of Carbon } \\
\text { Dioxide Emissions } \\
\text { by Enterprises (units) } \\
\text { in Beijing }\end{array}$ \\
\hline $\begin{array}{c}\text { Guidelines for } \\
\text { Accounting and }\end{array}$ \\
\hline
\end{tabular}




\begin{tabular}{|c|c|c|c|}
\hline Kerosene & 3.15 & $\mathrm{tCO}_{2} / \mathrm{t}$ & $\begin{array}{c}\text { Reporting of Carbon } \\
\text { Dioxide Emissions } \\
\text { by Enterprises (units) } \\
\text { in Beijing }\end{array}$ \\
\hline $\begin{array}{c}\text { Electric } \\
\text { power }\end{array}$ & 0.6101 & $\begin{array}{c}\mathrm{tCO}_{2} / \\
\mathrm{MWh}\end{array}$ & $\begin{array}{c}\text { Electric Power } \\
\text { Emission Factor } \\
\text { Released by National } \\
\text { Development and } \\
\text { Reform Commission } \\
\text { in 2015 }\end{array}$ \\
\hline Water & 0.000121954 & $\mathrm{t} / \mathrm{t}$ & Domestic Database \\
\hline
\end{tabular}

\subsection{Carbon emission activity level}

In the process of project construction, there are many types of materials and energies involved. In order to realize efficient and reliable calculation of data, it is necessary to screen out the main categories of carbon emissions and the main materials, energy resources and activity level data that affect carbon emissions. According to the carbon emission sources determined above, the carbon emissions during the construction of the Winter Olympics stadium is the sum of the carbon emissions from the use of materials, the transportation of materials and the use of energy in the stadium during the construction of the stadium and municipal supporting infrastructure, and the activity level data covers in the construction stage the consumption of building materials, transport distance and consumption of shifts.

Based on the above-mentioned calculation formula of carbon emission factor method, the carbon emission of building materials in the construction stage can be calculated according to the following formula:

$$
E_{S C}=\sum_{i=1}^{\mathrm{n}}\left(A D_{\mathrm{Z} T_{i}} \bullet E F_{Z T_{i}}\right)+\sum_{i=1}^{n}\left(A D_{Z T_{i}} \bullet S_{Z T_{i}} \bullet E F_{Z T S}\right)
$$

\section{Where:}

$\mathrm{E}_{S C}$-Carbon emissions from building materials $\left(\mathrm{tCO}_{2}\right)$; $\mathrm{AD}_{Z T}$-Consumption of building structural materials (t);

$\mathrm{EF}_{Z T}$-Carbon emission factor for building structural materials $\left(\mathrm{tCO}_{2} / \mathrm{t}\right)$;

i-category i building structural materials, i.e. material categories;

$\mathrm{EF}_{Z T S}$-Carbon emission factor from transport of building structural materials $\left(\mathrm{tCO}_{2} /(\mathrm{t} \cdot \mathrm{km})\right)$;

$\mathrm{S}_{Z T}$-Transport distance of building structural materials.

Carbon emissions from energy used during the construction stage are calculated according to the following formula:

$$
\begin{aligned}
E_{S G}= & \sum_{i=1}^{\mathrm{n}}\left(A D_{S G D_{i}} \bullet E F_{D}\right)+\sum_{i=1}^{n}\left(A D_{S G Y_{i}} \bullet E F_{Y}\right)+ \\
& \sum_{i=1}^{n}\left(A_{S G Q T_{i}} \bullet E F_{Q T}\right)
\end{aligned}
$$

Where:
$\mathrm{E}_{S G^{-}}$-Carbon emissions from the building during the construction stage $\left(\mathrm{tCO}_{2}\right)$;

$\mathrm{AD}_{S G D}$-Power consumption of a unit process during the construction stage $(\mathrm{kW} \cdot \mathrm{h})$;

$\mathrm{EF}_{D}$-Power emission factor $\left[\mathrm{tCO}_{2} /(\mathrm{kW} \cdot \mathrm{h})\right]$;

$\mathrm{AD}_{S G Y}$-Fuel consumption of a unit process during the construction stage $(\mathrm{t})$;

$\mathrm{EF}_{Y}$-Carbon emission factor from fuel consumption $\left(\mathrm{tCO}_{2} / \mathrm{t}\right)$;

$\mathrm{AD}_{S G Q T}$-Other energy consumption of a unit process during the construction stage (tce);

$\mathrm{EF}_{Q T}$-Carbon emission factor from other energy resources $\left(\mathrm{tCO}_{2} / \mathrm{tce}\right)$.

\section{Data management and feedback mechanism of carbon emissions}

According to the above-mentioned calculation method of carbon emissions, to obtain carbon emissions it is required to get the activity data, which needs to be recorded and sorted out by the construction site, and the carbon emission factor, which is measured and calculated based on the activity type.

For the sake of comprehensive and efficient statistics of activity data, it is necessary to formulate periodic plans of activity data monitoring. According to statistical methods and accuracy, the construction unit records the amount of building materials used, the number of construction machinery shifts and fuel consumption, as well as the number of transport vehicles used and fuel consumption in real time. A large amount of monitoring data obtained need to be systematically sorted out and categorized. The Winter Olympics stadium uses the statistical table in "Sustainability Reporting Guidelines" G4 issued by the Global Reporting Initiative (GRI) in Beijing to make monthly statistics of the activity level data of greenhouse gas emission sources and report it to form a monthly statement. Secondly, the data are calculated according to the carbon emission factor method to form monthly and quarterly statements of carbon emissions, based on which we can analyze the carbon emissions and come to the demand for emission reduction.

Furthermore, based on the construction conditions and the carbon emission reduction demand of the stadium, the construction process is reasonably optimized to form a comprehensive optimization scheme for carbon emission reduction. The carbon emissions of each quarter are reflected in the quarterly feedback, and measures to promote carbon emission reduction are implemented in accordance with the emission reduction scheme in the next construction process. The annual carbon emission data collected will form an annual statement of carbon emission management for further feedback and summary. With regular collection, calculation and feedback of carbon emission data, realtime monitoring of carbon emission data and construction of monitoring and feedback mechanism, the effective realization of objectives of carbon emission management is ensured. 


\section{Management model and working system of carbon emissions}

Based on the above-mentioned objectives and principles as well as scope of carbon emission management, and monitoring, calculation and feedback working mechanism of carbon emission data, a complete management model of carbon emissions is constructed and shown in the figure below.

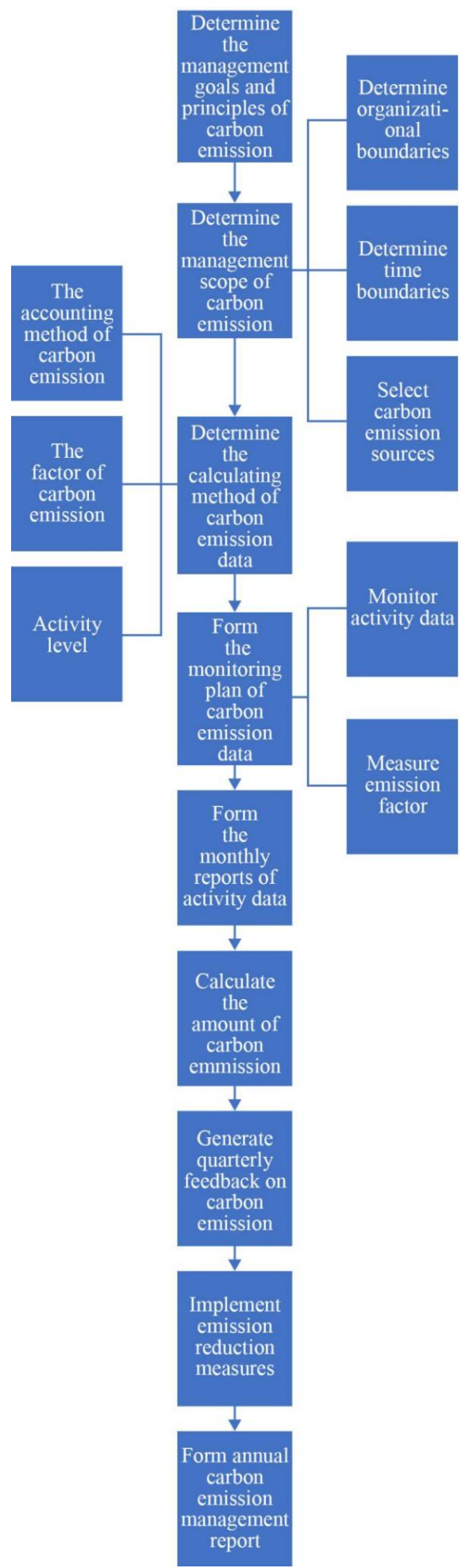

Fig. 3. Management Model of Carbon Emissions for a Winter Olympics Stadium
On the basis of the management model of carbon emissions, the overall planning of carbon emission management in the construction stage needs to take several stages of raw material production, transportation and construction into consideration. When thinking of comprehensive measures for carbon emission reduction, it is necessary to start with processes like design, procurement, and construction. The whole process, which shall not affect the production progress and product functions, involves coordination and cooperation of multiple departments, and reduces greenhouse gas emissions as much as possible through multi-level and multi-dimensional comprehensive measures.

In order to implement all the tasks in the carbon emission management model, and optimize the carbon emission reduction work, the carbon emissions are scientifically predicted, monitored through statistics and optimized, so as to establish a relatively complete working system. At the same time, according to the organizational structure and division of responsibilities of the enterprise, a detailed work flow for carbon emission management is formulated (Figure 4).

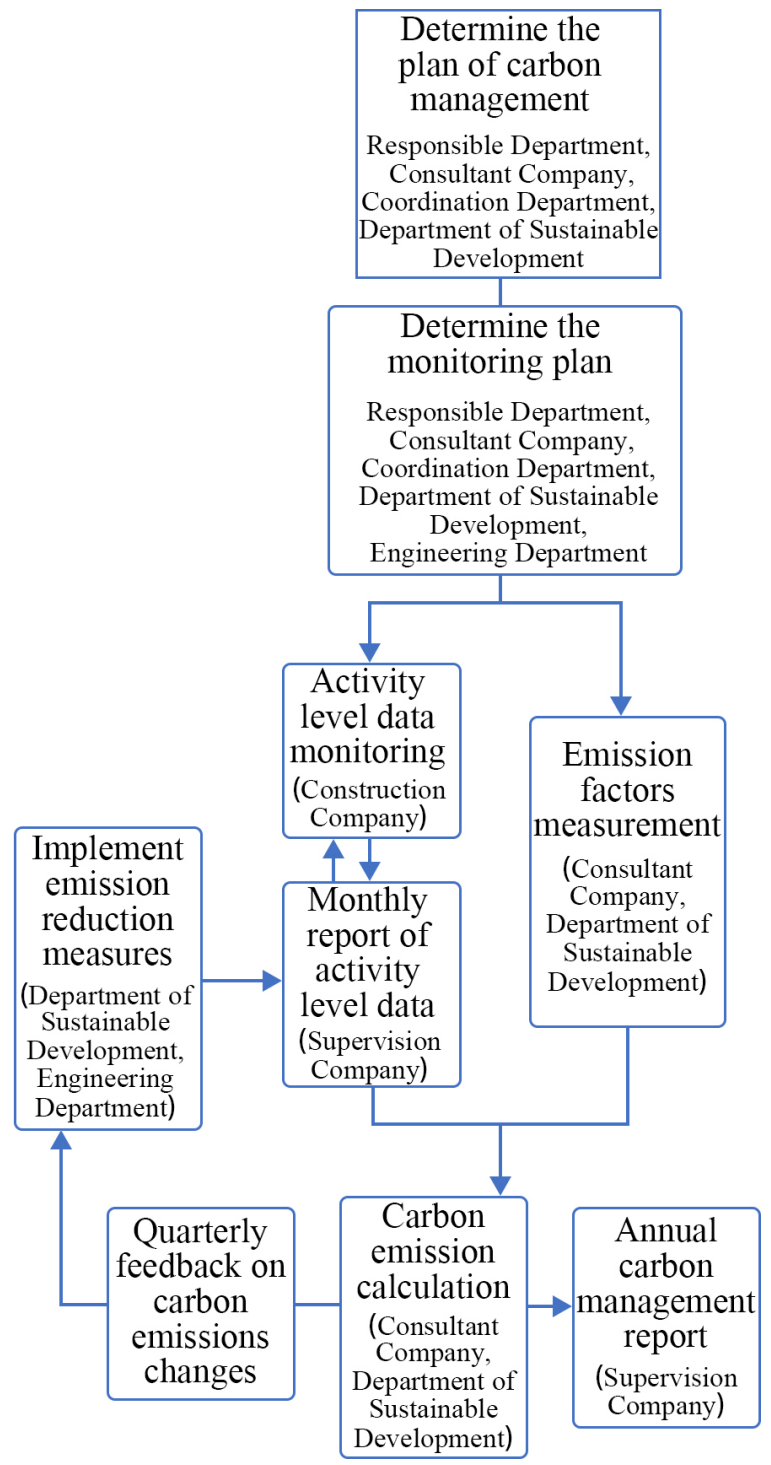

Fig. 4. Work Flow and Division of Responsibilities of Carbon Emission Management 
In order to regulate the monitoring and accounting activities of greenhouse gas emissions from enterprises, the construction of the stadium refers to the basic contents of the enterprise monitoring plan template issued by the National Development and Reform Commission to formulate a monitoring plan, which is then revised according to the specific conditions of the Olympic Games. The monitoring plan mainly includes:

a.Version and revision of the monitoring plan;

b.Description of body of the report;

c.Description of accounting boundaries and major emission facilities;

d.Determination method for activity data and emission factors;

e.Relevant regulations on internal quality control and quality assurance of data.

Besides the monitoring plan, each responsible unit shall regularly report monthly, quarterly, semi-annual and annual statements. At the same time, it also focuses on strengthening the supervision and implementation of carbon emission reduction measures during the construction and office visits of the stadium.

\section{Conclusion}

In order to fulfill the promise of carbon emission reduction made by Beijing in hosting the 2020 Winter Olympics, this paper takes it as one of the important control systems of carbon emission management to optimize the carbon emissions during the construction of the stadium, and taking a stadium for the 2020 Winter Olympics as an example, constructs the carbon emission management model during the construction process. First of all, by referring to the relevant methodologies at the enterprise and organizational levels of ISO16064, the author develops six principles of carbon emission management, namely correlation, completeness, consistency, accuracy, transparency and avoidance of repetition. Secondly, the paper defines the construction and installation stage as the time boundaries, defines the organization boundaries according to the right of control method, and determines the carbon emission source of the stadium based on the feasibility of the decision tree and accounting. Furthermore, the carbon emission factor method is selected as the calculation method of carbon emissions to provide data support for carbon emission management. Finally, in order to implement carbon emission management, a working system of prediction, monitoring through statistics and feedback mechanism has been established, and the work flow of enterprise's organizational structure has been formulated. The comprehensive management model of carbon emission reduction for stadium construction follows the standard systems of carbon footprint and carbon offsetting at home and abroad, is universally applied in different public buildings, and is expected to become the carbon emission management model suitable for a wider range of public building construction stages in subsequent studies.

This research has been funded by the research programs The Study on Synergistic Technology Strategy for the Underground Block Space of Urban Railway Terminals Identified by Green Efficiency (W201813216) ,Research on Carbon Emission Management Model and Design Strategy Based on the Construction Process of Winter Olympic Games Stadium (W2018132-18), and The Study on Interaction between Underground Space and Ecological Landscape in the View of Green Efficiency (X20020) by "Beijing Advanced Innovation Center For Future Urban Design, Beijing University of Civil Engineering And Architecture".

\section{References}

1. Tongyu Sun, Sha Liu, Wenbin Shi, The Future Signifivance and Implementation Path of Net-Zero Energy Buildings (NZEB), AT,2020(8), 18-23(2020)

2. Zhihui Zhang, Chunjing Shang, Kun Qian, Life Cycle Carbon Emission Assessment of Buildings, CE,2010(2),44-46(2010)

3. Yiming Liu, Nianxiong Liu, The Significance of Carbon Emission Calculation in Building Life Cycle Assessment ,DC,2020(3),46-51(2020)

4. Chunjing Shang, Chenglong Chu, Zhihui Zhang, Comparison of Carbon Emission during the Life Cycle of Different Structures, SB,27(012),6973+98(2011)

5. Yongjiang Li,Ideas and Basic Principles for Compiling Greenhouse Gas Inventory ,PCI, (10),5659(2010) 